\title{
UNA APROXIMACIÓN A LOS PROBLEMAS ACTUALES DEL BLANQUEO DE CAPITALES Y EL DELITO FISCAL
}

\section{CURRENT PROBLEMS OF MONEY LAUNDERING AND TAX CRIME}

\author{
DAVID CARRIÓN MORILLO*
}

\begin{abstract}
Sumario: I. INTRODUCCIÓN. II. EL BLANQUEO DE CAPITALES Y SU PREVENCIÓN. III. EL DELITO FISCAL Y SU RELACIÓN CON EL BLANQUEO. IV. REFLEXIONES FINALES.
\end{abstract}

Summary: I. INTRODUCTION. II. ANTI MONEY LAUNDERING. III. TAX CRIME AND ITS LINKS WITH MONEY LAUNDERING. IV. FINAL CONCLUSIONS.

Resumen: El delito de blanqueo de capitales y el delito fiscal han sufrido varias modificaciones desde su recepción en la legislación penal española, siendo especialmente importantes las que han afectado a algunos de sus aspectos esenciales. Algunas de ellas han sido muy contestadas por la doctrina, sobre todo la amnistía fiscal amparada en el texto del Real Decreto-ley 12/2012, de 30 de marzo, por el que se introducen diversas medidas tributarias y administrativas dirigidas a la reducción del déficit público. En este artículo se tratará de iluminar las sombras de estos delitos y de su relación, además de tratar de despejar algunas dudas sobre su más plausible interpretación.

Abstract: The crime of money laundering and tax crime have undergone several modifications since its incorporation in the Spanish penal law, being especially important the ones that affected some of its essential aspects. Some of them have been answered by the doctrine, especially the tax amnesty covered in the Real Decreto-ley 12/2012, of 30 March, where various tax and administrative measures were included with the aim of decreasing the public deficit. This article will attempt to enlighten the shadows of these crimes and their relationship, and also try to clear up some doubts about its most plausible interpretation.

Palabras clave: blanqueo de capitales, autoblanqueo, fraude fiscal, amnistía fiscal, regularización fiscal.

Keywords: money laundering, self-laundering, tax fraud, tax amnesty, tax adjustment.

\section{INTRODUCCIÓN}

\footnotetext{
* Abogado. Profesor Titular de Derecho Financiero y Tributario. Universidad Europea de Madrid 
La figura del blanqueo de capitales puede retrotraerse a mucho tiempo atrás, aunque su tipificación, al menos en España, sea relativamente muy moderna. En realidad, blanquear capitales no significa otra cosa más allá de querer legalizar unos bienes de origen ilegal; dicho de otro modo y aún más sencillo: hacer lícito lo ilícito. Los delincuentes siempre han encontrado muchos problemas a la hora de introducir en el mercado y legalizar, por tanto, los bienes procedentes de sus actividades delictivas. Los propios piratas ya tuvieron muchas complicaciones para vender los bienes procedentes de sus botines a los comerciantes (algunos de estos hacían negocio por el precio tan bajo que pagaban por esas mercancías). El riesgo era enorme, pues en cualquier momento podían perder el botín que habían obtenido con sus fechorías, ya fuera por la actuación de los representantes de la ley o por la ambición desmesurada de sus compinches. Así ha sido descrito acertadamente: "Una de las razones por las cuales los piratas que regresaban derrochaban sus riquezas era que les resultaba muy difícil protegerlas" ${ }^{1}$.

No debemos quedarnos en el siglo XVII, por lo que si avanzamos en el tiempo, nos encontramos con la irrupción en el panorama internacional de los narcotraficantes, que son aquellos delincuentes que logran pingües beneficios con la venta de drogas ilegales. En el siglo XX ha sido uno de los negocios más lucrativos junto a la venta ilegal de armas ${ }^{2}$. Los narcotraficantes tenían, por encima de todo, un mayúsculo problema: tenían que legalizar los bienes que habían obtenido de manera ilícita. Por ello, tuvieron la necesidad de contar con la ayuda de otras personas que les ayudaban a realizar este tipo de transformaciones, en especial aparecieron multitud de contables y abogados. Los estados nacionales nunca supusieron una barrera para este tipo de delincuencia criminal organizada; era tanto el caudal de dinero que ellos manejaban que no tenían problema en encontrar bancos que lo cobijasen, estuvieran donde estuvieran estos.

Debido a los efectos perjudiciales para la economía, en general, y para la macroeconomía, en particular, consecuencia de estas maniobras ilegales, los estados, organizaciones y organismos internacionales tuvieron que adoptar medidas para perseguir a esta clase de delincuencia. Como ha sido brillantemente expuesto, la nocividad del blanqueo de capitales se muestra en una doble trayectoria: "primeramente colectiva, perturbando las condiciones generales del mercado que permiten el normal desarrollo de la iniciativa privada, a la vez que la satisfacción de los intereses de consumidores y usuarios, en segundo término, individual, poniendo en peligro -si no lesionando- las legítimas expectativas de los particulares que aspiran a participar, cada cual desde su propia posición, en ese mismo juego de relaciones económicas”3 ${ }^{3}$.

\footnotetext{
${ }^{1}$ R. ZACKS, El cazador de piratas. La historia secreta del capitán Kidd, traducción de Ricard Martínez i Muntada, Círculo de Lectores, Barcelona, 2004, p. 328.

${ }^{2}$ Resulta imprescindible leer la evolución de las drogas y de los que se aprovecharon de ellas, en cualquier sentido, en especial en su último capítulo ("Bosquejo de la situación mundial contemporánea”) de la obra magna de este tema, escrita por A. ESCOHOTADO: Historia general de las drogas, Espasa Calpe, Madrid, 2002, pp. 1073-1124.

${ }^{3}$ E. A. FABIÁN CAPARRÓS, El delito de blanqueo de capitales, Colex, Madrid, 1998, p. 229.
} 
Nuestro país, España, no ha sido una excepción en lo tocante a aprobar una legislación que tipificase las conductas delictivas que dimanaban de las fechorías de estos delincuentes. El estado español tampoco ha tenido plena libertad para legislar sobre este tema, ya que en los últimos tiempos ha tenido que transponer las directivas comunitarias correspondientes. En este artículo, por lo tanto, se van a ir desgranando las definiciones conceptuales de los tipos delictivos del blanqueo de capitales y del delito fiscal, pues este último se ha convertido en uno de los delitos previos o antecedentes que más se utiliza para soportar la condena por blanqueo de capitales. También se analizará la interpretación de la más importante jurisprudencia y doctrina al respecto. Todo eso es lo que trataremos de ilustrar a lo largo de este texto.

\section{EL BLANQUEO DE CAPITALES Y SU PREVENCIÓN}

¿Cuándo se regula por primera vez en España el delito de blanqueo de capitales? ¿Cuál es la legislación que origina su tipificación? Es evidente que la primera vez que se reguló el blanqueo de capitales no tenía el alcance de la tipificación actual, pero, aun así, hay que reconocer que la Ley Orgánica 1/1988, de 24 de marzo, significó la inclusión, en la redacción del artículo 546 bis f) del Código Penal de 1973, del blanqueo de bienes procedente de la venta o tráfico de drogas, cuestión que se amplió con la ratificación de España del Convenio de Viena de 20 de diciembre de 1988 el 30 de julio de $1990^{4}$. No es, por el contrario, hasta 1995, con la aprobación y entrada en vigor del actual Código Penal cuando se va a uniformar y agrupar las conductas de blanqueo de capitales en su artículo 301. Pese a esa unificación, se volvió a modificar con la reforma que sufrió nuestro Código Penal por la implantación de la Ley Orgánica 15/2003, de 25 de noviembre. La última modificación, hasta que ha entrado en vigor la reforma del Código Penal de este mismo año 2015, se produjo con la entrada en vigor de la Ley Orgánica 5/2010, de 22 de junio ${ }^{5}$. Asimismo, como veremos más adelante, también son muy importantes las leyes aprobadas que ordenan la prevención del blanqueo de capitales, ya que se han utilizado, en no pocas ocasiones, para modificar cuestiones que no se circunscriben a la mera prevención del delito sino al propio tipo delictivo: la primera fue la Ley 19/1993, de 28 de diciembre, sobre determinadas medidas de prevención del blanqueo de capitales y la última, que derogó la anterior, ha sido la Ley 10/2010, de 28 de abril, de prevención del blanqueo de capitales y de la financiación del terrorismo.

\footnotetext{
4 Además existieron otras normas entonces que, aunque no regularon directamente el blanqueo de capitales, tuvieron consecuencias sobre sus efectos: Declaración de Basilea aprobada el 12 de diciembre de 1988 por el Comité sobre Regulación y Supervisión Bancaria -y la adhesión a esta Declaración de Basilea de la Asociación Española de Banca Privada (A.E.B.) y de la Confederación Española de Cajas de Ahorro (C.E.C.A.)-, entre otras. Véase J. M. PALMA HERRERA, Los delitos de blanqueo de capitales, Edersa, Madrid, 2000, pp. 865-957.

${ }^{5}$ Véase la cuestión en los siguientes textos: A. MUÑOZ VILLARREAL, "El delito de blanqueo de capitales y los delitos contra la Hacienda Pública”, Revista Jurídica de Castilla y León, n 34, septiembre de 2014, p. 3; F. J. MUÑOZ CUESTA, "El delito de blanqueo de capitales. Alcance después de la reforma del art. 301 por LO 5/2010: autoblanqueo y delito fiscal”, Revista Aranzadi Doctrinal, n 2, 2013, pp. 11-13.
} 
Básicamente, lo que han supuesto estos cambios legislativos en la regulación, y consecuente tipificación del blanqueo de capitales, es una concreción y depuración de este delito, pues el legislador ha ido perfilando los elementos del tipo delictivo y el castigo del delito en función de la evolución de las consecuencias económicas, especialmente macroeconómicas, y sociales del blanqueo. De este modo, se ha podido constatar un aumento de estos delitos, tanto cuantitativa como cualitativamente. Con respecto a la cuestión cuantitativa, se ha comprobado que ha aumentado, en gran medida, el número de delitos de blanqueo de capitales cometidos ${ }^{6} \mathrm{y}$, en referencia a la cuestión cualitativa, se observa en los últimos tiempos que las cantidades de dinero de origen ilícito blanqueadas son mucho mayores, lo que supone un perjuicio mayúsculo para las arcas del Estado, que ven reducida su recaudación en unos tiempos que han sido duros para la mayoría de ciudadanos. El hecho de que las organizaciones criminales, o tan solo particulares, contasen también con más instrumentos para blanquear el dinero, como bancos o paraísos fiscales, no solo ha obligado a modificar la tipificación del delito en tantas ocasiones, sino también ha derivado en una legislación muy importante sobre su prevención ${ }^{7}$.

En la actualidad, el tipo delictivo clave de blanqueo de capitales, tal y como hoy está definido, viene descrito en el artículo 301.1 del Código Penal: "El que adquiera, posea, utilice, convierta, o transmita bienes, sabiendo que éstos tienen su origen en una actividad delictiva, cometida por él o por cualquiera tercera persona, o realice cualquier otro acto para ocultar o encubrir su origen ilícito, o para ayudar a la persona que haya participado en la infracción o infracciones a eludir las consecuencias legales de sus actos, será castigado con la pena de prisión de seis meses a seis años y multa del tanto al triplo del valor de los bienes”. De la descriptiva redacción de este artículo se desprende que debe existir un delito previo, subyacente, precedente o antecedente al blanqueo de capitales, pues los bienes mencionados en el texto con tan poca concreción y detalle "tienen su origen en una actividad delictiva”. En una práctica ya habitual de nuestro legislador, en la que este ha abusado en demasía, el artículo no concreta cuáles son esas actividades delictivas, y el no incluir una lista de delitos subyacentes ha obligado a interpretar ese supuesto dando lugar a la disparidad de criterios.

Además, el blanqueo de capitales, según se describe en el artículo, deja abierto el tema de quiénes pueden perpetrar el delito, pues parece que se castiga tanto si se ha realizado por el mismo sujeto que también llevó a cabo el delito previo como si se tratase de una tercera persona. Por ello, el hecho de que la persona que posea esos bienes con origen ilícito pueda ser la misma que había realizado la actividad delictiva que supone el delito subyacente y también "realice cualquier otro acto para ocultar o encubrir su origen ilícito” es lo que se denomina como autoblanqueo, mientras que también parece que existe la tipificación de aquel tercero que, o bien realizó la actividad delictiva previa o bien se implicó más tarde en el blanqueo de capitales "para ayudar a la persona que haya participado en la infracción o infracciones a eludir las

\footnotetext{
${ }^{6}$ Se puede comprobar consultando las estadísticas de los delitos de blanqueo de capitales publicadas en la página del Instituto Nacional de Estadística, sección Seguridad y Justicia: www.ine.es.

${ }^{7}$ Véase las memorias publicadas por el Servicio Ejecutivo de la Comisión de Prevención del Blanqueo de Capitales (S.E.P.B.L.A.C., en adelante).
} 
consecuencias legales de sus actos”. El legislador ha tratado de resolver la posible confusión sobre qué delito comete el tercero que pudiese participar en un presunto supuesto de blanqueo de capitales modificando, por Ley Orgánica 1/2015, de 30 de marzo, que, a su vez, modificaba el Código Penal, el artículo 298.1 del Código Penal vigente que reza, en directa consecuencia, lo siguiente: "El que, con ánimo de lucro y con conocimiento de la comisión de un delito contra el patrimonio o el orden socioeconómico, en el que no haya intervenido ni como autor ni como cómplice, ayude a los responsables a aprovecharse de los efectos del mismo, o reciba, adquiera u oculte tales efectos, será castigado con la pena de prisión de seis meses a dos años”.

En este supuesto enunciado del artículo 298.1, se define lo que ya lo doctrina había calificado de receptación, y no de blanqueo de capitales, es decir, se menciona expresamente que el tercero debe cumplir dos requisitos además de, por supuesto, ayudar a los responsables del delito: por un lado, el tercero debe ejercer su ayuda al delincuente "con ánimo de lucro y con conocimiento de la comisión de un delito contra el patrimonio o el orden socioeconómico” y, por otro lado, el legislador exige que este tercero "no haya intervenido ni como autor ni como cómplice", el dato clave para considerarse receptación ${ }^{8}$. Se observa, por tanto, que el legislador, en esta última reforma, ha sido muy escrupuloso y preciso a la hora de redactar este artículo, a diferencia de lo poco concreto y lo tremendamente abierto de la redacción del blanqueo de capitales del 301.1, en el que ni tan siquiera, como decíamos, se menciona una lista de delitos previos.

Si es la misma persona la que ha cometido directamente, o ha sido cómplice, del delito subyacente y también del propio blanqueo de capitales, ¿es punible su conducta como blanqueo de capitales? ¿Es punible, por tanto, el autoblanqueo? La doctrina estaba dividida al respecto. Una parte de ella entendía que no era punible, por lo que negaba que los autores y partícipes en el delito precedente pudieran ser castigados como autores o partícipes del delito de blanqueo de capitales. Para ello, esgrimían, principalmente, alguna de estas dos tesis: "La primera afirmaba que el blanqueo de capitales es un delito posterior copenado con relación al delito previo, lo que suponía partir de la identidad de bienes jurídicos afectados por el delito previo y el posterior comportamiento. La segunda consideraba aplicable el principio general de inexigibilidad de otra conducta, sobre la base de que no se le puede exigir al delincuente que se descubra, esto es, no se puede castigar al delincuente por encubrir el origen ilícito de los bienes derivados de su actividad delictiva, pues ello equivaldría a exigirle que declarase contra sí mismo”`. La primera de ellas llegaba a tal conclusión al considerar que los dos actos son copenados, es decir, que existiría un concurso de normas en el que la relación directa entre el hecho

\footnotetext{
${ }^{8}$ La Ley Orgánica 5/2010, de 22 de junio, que modificaba el Código Penal, también supuso la modificación de la redacción del nombre de su Capítulo XIV, que se denominaba "De la receptación y otras conductas afines". Con esta reforma, y consecuente modificación, paso a su denominación actual: "De la receptación y el blanqueo de capitales". Como se ve a primera vista, pasa a tener más peso, por tanto, el blanqueo de capitales, que se cita con nombre propio, aunque, en verdad, este cambio resultó intrascendente, así que puede ser calificado de simple retoque.

${ }^{9}$ P. FARALDO CABANA, "Antes y después de la tipificación expresa del autoblanqueo de capitales", Estudios Penales y Criminológicos, vol. XXXIV, 2014, pp. 46-47.
} 
previo y el posterior hace que el castigo del primer hecho incluya todo el desvalor propio de ambos hechos, en una clara aplicación del principio de consunción ${ }^{10}$. La segunda de las tesis expuestas llega también a la conclusión de que no sería punible el autoblanqueo, en este caso, por no poder exigir al delincuente que se autoinculpe ${ }^{11}$.

Hoy en día, pese a la opinión de buena parte de la doctrina, se ha demostrado justo lo contrario, a causa de los cambios legislativos y la interpretación que han realizado los tribunales de justicia. Por ello, no hay ninguna duda de que el autoblanqueo es punible, aunque solo fuera por la razón principal de que, ya incluso antes de la reforma del 2010, el legislador, en el artículo 301.1, no había señalado que el responsable de este delito no podía haber participado en la comisión del delito previo, como, por el contrario, lo había señalado en el artículo 298.1, con lo que dejaba claramente abierta la posibilidad de castigar a los intervinientes en el delito previo al blanqueo $^{12}$.

Leyendo la redacción actual del artículo 301.1 ya comentada, no cabe duda de que el autoblanqueo es punible, pues se dice que la actividad delictiva previa puede ser “cometida por él o por cualquiera tercera persona”. Igualmente, no cabe aducir al sancionar por blanqueo al mismo individuo que había cometido el delito previo que se haya vulnerado el principio non bis in ídem, puesto que, con la redacción actual del artículo, se separan ambas conductas ${ }^{13}$ e incluso se podría llegar a castigar al delincuente que ha realizado el blanqueo de capitales pese a que no exista condena expresa por el delito previo, bastaría con la prueba indiciaria, que ha sido admitida por la jurisprudencia hace mucho tiempo ${ }^{14}$.

Es evidente que la magnitud del delito de blanqueo de capitales va mucho más allá de su estricta inclusión en el Código Penal: es un delito que afecta, de manera notoria, en el orden social y económico. Por ello, el legislador se ha visto obligado a legislar no solo sobre los elementos del tipo delictivo sino también sobre su prevención. La Ley 10/2010, de 28 de abril, de prevención del blanqueo de capitales y de la financiación del terrorismo ha supuesto la imposición de una cantidad gigantesca, y sin duda excesiva, de obligaciones a muchos profesionales, en especial jurídicos, que pueden ayudar, en cierta medida, al delincuente a blanquear su dinero o sus bienes. Los sujetos obligados por esta ley son numerosísimos, pero se pueden destacar, de entre ellos, los siguientes: entidades financieras; promotores inmobiliarios y quienes ejerzan

\footnotetext{
${ }^{10}$ Véase J. M. PALMA HERRERA, Los delitos de blanqueo de capitales, cit., pp. 390-395.

${ }^{11}$ Véase I. BLANCO CORDERO, El delito de blanqueo de capitales, Aranzadi, Pamplona, 1997, p. 470.

12 Véase esta opinión en los siguientes textos: P. FARALDO CABANA, "Antes y después de la tipificación expresa del autoblanqueo de capitales", cit., p.49; J. GARCÍA SAN MARTÍN, "La concreción del delito antecedente en el blanqueo de capitales”, Diario La Ley, nº 8587, Sección Doctrina, 21 de Julio de 2015, Ref. D-293.

${ }^{13}$ Véase la STS 974/2012, de 5 de diciembre, que, en ese mismo sentido, afirma: "se trata de conductas que adquieren relevancia penal y criminológica autónoma y permiten su aplicación conjunta como suma de actividades delictivas de distinto carácter y de bienes jurídicos de distinta naturaleza afectados, por lo que la norma del delito penal no abarca la total antijuricidad del hecho".

${ }^{14}$ Véanse, a título de ejemplo, las SSTS 811/2012, de 30 de octubre, y, de este mismo año, 77/2015, de 4 de febrero.
} 
de agentes o intermediarios profesionales en la compraventa de inmuebles; auditores de cuentas, contables externos y asesores fiscales; notarios y registradores, abogados y procuradores.

Eran tantísimas las obligaciones que establecía esta ley que no tardaron en llegar las dudas y las propuestas de los muchos sujetos obligados por ella ${ }^{15}$. No sabemos si debido a esa presión popular, o simplemente por iniciativa propia, el mismo legislador redujo el cúmulo de obligaciones y su aplicación con la aprobación de su reglamento ${ }^{16}$. Si nos centramos en uno de los grupos profesionales más afectados por la legislación de prevención del blanqueo de capitales, como son los abogados, podremos ver que la Ley 10/2010 les impuso unas obligaciones que, en síntesis, se pueden dividir en tres clases: de diligencia debida (normales, simplificadas o reforzadas), de información y de control interno. Gracias a la publicación de su reglamento, las obligaciones de control no se exigen a los abogados que cumplan dos requisitos: su volumen de negocios anual no supere los dos millones de euros y que cuenten, además, con una plantilla inferior a diez empleados.

Aunque no tengan que cumplir con la obligación de control la mayoría de abogados, en virtud de esos dos requisitos antes enunciados, aún tienen que cumplir con las otras dos clases de obligaciones que, a su vez, pueden desglosarse en las siguientes: deber de conocimiento del cliente, deber de determinar el origen de los fondos, deber de conservar la documentación, deberes de comunicación y colaboración y, finalmente, deber de abstención. Estas obligaciones o deberes requieren una pequeña explicación sobre en qué se concretan. En primer lugar, el deber de conocer a su cliente, lo que supone es que todos los abogados deben realizar un análisis de riesgo de sus clientes por escrito, para así poder acreditarlo ante las autoridades pertinentes. En segundo lugar, el deber de determinar el origen de los fondos supone que el abogado debe conocer la procedencia de los fondos de su cliente. En tercer lugar, el deber de conservar la documentación supone la obligación de conservar los documentos durante diez años. En cuarto lugar, los deberes de comunicación y colaboración han resultado problemáticos para los abogados, pues, no pocos de ellos, consideraban que este deber vulneraba uno de los principios básicos de su profesión: el secreto profesional.

Hay que resaltar que como ha puesto de manifiesto la jurisprudencia, aunque tampoco hubiese hecho falta en realidad, este secreto profesional, al igual que cualquier otro principio básico o no, no puede ser ilimitado. Por eso, y pese a que sea un pilar profesional en el que se apoya la consecución del trabajo de los abogados, se puede resumir la cuestión con las palabras de uno de los mayores expertos en esta materia en España: "Mientras en la vertiente de la defensa, el secreto es esencial, ya que sin

\footnotetext{
${ }^{15}$ A pesar de ser generalizada la oposición a la ley por parte de las profesiones obligadas por la misma, en el otro extremo, se ha llegado a pedir "tipificar como un nuevo delito en el Código Penal la conducta consistente en el ofrecimiento al mercado de servicios idóneos para la defraudación tributaria o el blanqueo de capitales". J. A. MATEOS MARTÍN, "El reto de la prevención del blanqueo de capitales en un mundo globalizado", RDUNED. Revista de Derecho UNED, n 12, 2013, p. 491.

${ }^{16}$ Se trata del Real Decreto 304/2014, de 5 de mayo, por el que se aprueba el Reglamento que desarrolla la Ley 10/2010 de 28 de abril, de prevención del blanqueo de capitales y de la financiación del terrorismo.
} 
respetarlo no hay defensa posible, en las demás vertientes de la actividad profesional, el secreto es dispensable y la ley puede limitarlo"17. En quinto y último lugar de estas obligaciones de prevención, el deber de abstención de ejecución supone que el abogado debe abstenerse de ejecutar la operación que le haya solicitado su cliente si encontrase indicios de blanqueo de capitales, notificándoselo al S.E.P.B.L.A.C., esto quiere decir que no es necesario que el abogado tenga la certeza, basta que existan indicios. Como vemos, el legislador le ha dado mucha importancia a la prevención del blanqueo de capitales $^{18}$, esperemos, por tanto, que estos controles sean efectivos.

\section{EL DELITO FISCAL Y SU RELACIÓN CON EL BLANQUEO}

El tipo básico del delito fiscal o tributario viene recogido en el artículo 305 del Código Penal. Según su texto, este delito consistiría en defraudar, por acción u omisión, a la Hacienda Pública eludiendo el pago de tributos, cantidades retenidas o que se hubieran debido retener o ingresos a cuenta de retribuciones en especie, obteniendo indebidamente devoluciones o disfrutando también indebidamente de beneficios fiscales, siempre que la cuantía de lo defraudado exceda de 120.000 euros. Se puede añadir que se trata de un delito doloso, que requiere en su autor la existencia de dolo o ánimo de defraudar; por tanto, no basta la mera cuantía de la deuda superior a $120.000 €$ para que exista delito. Como había sucedido con el blanqueo de capitales, este delito ha tenido varias reformas, pero la más importante de ellas es la que se produjo en el año 2012.

Más allá del propio y concreto delito tributario y su tipo básico, hay que resaltar que si bien el blanqueo de capitales, como ya señalamos, afecta a la economía de un país, con mayor virulencia actúa el fraude fiscal, según las razones descritas en la exposición de motivos de la Ley 36/2006, de 29 de noviembre, de medidas para la prevención del fraude fiscal: "supone una merma para los ingresos públicos, lo que afecta a la presión fiscal que soportan los contribuyentes cumplidores; condiciona el nivel de calidad de los servicios públicos y las prestaciones sociales; distorsiona la actividad de los distintos agentes económicos, de tal modo que las empresas fiscalmente cumplidoras deben enfrentarse a la competencia desleal de las incumplidoras; en definitiva, el fraude fiscal constituye el principal elemento de inequidad de todo sistema tributario". Toda esta argumentación se puede resumir en que el Estado y sus “incesantes necesidades de recursos exigen recaudaciones fiscales sin lagunas" ${ }^{19}$.

\footnotetext{
${ }^{17}$ N. SÁNCHEZ STEWART, Abogados y prevención del blanqueo de capitales. Manual básico, Ley 57, Málaga, 2014, p. 68.

${ }_{18}$ Pese a la importancia que tiene la prevención para el legislador, hay que recordar que España fue condenada por el Tribunal de Justicia de la Unión Europea, el 1 de octubre de 2009, por incumplir la directiva comunitaria que trata de prevenir que el sistema financiero sirviese para blanquear capitales y financiar el terrorismo. Este tema puede verse analizado con mayor extensión en M. V. VEGA SÁNCHEZ, Prevención del blanqueo de capitales y de la financiación del terrorismo. Nueva Ley 10/2010, de 28 de abril, Ramón Areces, Madrid, 2011, pp. 49-56.

19 J. C. MARTINEZ, El fraude fiscal, traducción de José Barrales Valladares, Fondo de Cultura Económica, México, 1989, p.15.
} 
La Ley Orgánica 7/2012, de 27 de diciembre, por la que se modifica la Ley Orgánica 10/1995, de 23 de noviembre, del Código Penal en materia de transparencia y lucha contra el fraude fiscal y en la Seguridad Social supuso el último eslabón, de momento, de una larga cadena que trataba de evitar el fraude fiscal en España. En concreto, las medidas tributarias descritas en esta ley se pueden resumir en los puntos siguientes $^{20}$ :

En primer lugar, la instauración de un tipo agravado que ofrezca respuesta a los fraudes especiales de gravedad superior. Este tipo agravado se ha sustanciado en la creación del artículo 305 bis del Código Penal, que eleva la pena de prisión establecida por el delito fiscal básico del artículo 305. Para que exista agravación en la pena, según este nuevo artículo, tiene que haberse producido alguna de las siguientes circunstancias: la cuantía de la cuota defraudada excede de 600.000 euros $^{21}$; la defraudación se haya cometido en el seno de una organización o de un grupo criminal; o bien, la utilización de personas físicas o jurídicas o entes sin personalidad jurídica interpuestos, negocios o instrumentos fiduciarios o paraísos fiscales o territorios de nula tributación oculte o dificulte la determinación de la identidad del obligado tributario o del responsable del delito, la determinación de la cuantía defraudada o del patrimonio del obligado tributario o del responsable del delito.

Consecuencia de esto, a su vez, es que el plazo de prescripción del delito fiscal aumenta a diez años en aplicación del artículo 131 del Código Penal, con la intención de obstaculizar la impunidad de conductas tan graves. Sin embargo, si recordamos que la prescripción tributaria es de cuatro años, pudiera parecer que podía estar en contradicción con este precepto legal. La cuestión, por tanto, como tantas otras, ha sido resuelta por la jurisprudencia. La sentencia del Tribunal Supremo núm. 952/2006, de 6 de octubre, zanja, con rotundidad, esta controversia declarando, mediante el desarrollo de dos sólidos argumentos, que no existe contradicción: el primero de ellos señala que el delito se somete legalmente a plazos más largos que la infracción tributaria por ser de mayor gravedad" ${ }^{22}$, y el segundo argumento concluye que "de tal prescripción administrativa no se sigue en absoluto como efecto necesario la desaparición de todo bien jurídico merecedor de tutela", por lo que "la prescripción de la deuda tributaria no afecta a su exigencia en vía penal”23.

\footnotetext{
${ }^{20}$ Para más detalles, véase D. CARRIÓN MORILLO, "Los intocables de Eliot Ness. A propósito de la lucha contra el fraude fiscal”, Revista Aranzadi de Derecho de Deporte y Entretenimiento, n 39, abriljunio de 2013, pp. 563-567.

${ }^{21}$ Algunos autores han manifestado que, aunque parezca una cantidad elevada, se trataría, más bien, de un privilegio: "Si se compara, por ejemplo, con la estafa, resulta que la pena es la misma, de uno a seis años de prisión, si la cuantía supera los cincuenta mil euros, mientras que en el delito contra la Hacienda Pública se han de superar los seiscientos mil euros”. A. SERRANO GÓMEZ y A. SERRANO MAÍLLO, "La reforma de los delitos contra la Hacienda Pública y contra la Seguridad Social", RDUNED. Revista de Derecho UNED, n ${ }^{\circ}$ 14, 2014, p. 564.

${ }^{22}$ Véanse también las SSTS 1688/2000, de 6 de noviembre; 1807/2001, de 30 de octubre, y 44/2003, de 3 de abril.

${ }^{23}$ Véanse, igualmente, las SSTS 1336/2002, de 15 de julio; 2115/2002, de 3 de enero, y 751/2003, de 28 de noviembre, entre otras.
} 
En segundo lugar, esta ley va a posibilitar la persecución de las tramas organizadas de fraude tributario mediante la facilitación de la denuncia inmediata una vez alcanzada la cantidad mínima de defraudación. En tercer lugar, va a acrecentar las posibilidades de cobro de la deuda tributaria impagada impidiendo la detención del procedimiento administrativo por el proceso penal. Esta medida se ha concretado en la modificación del artículo 305.5 del Código Penal, que, taxativamente, así lo declara: "La existencia del procedimiento penal por delito contra la Hacienda Pública no paralizará la acción de cobro de la deuda tributaria”. El juez, de todas formas, aunque de modo excepcional, podrá determinar la suspensión de esta medida en los casos donde el cobro de la deuda tributaria o la ejecución de las garantías, en su defecto, pudiese ocasionar un daño o perjuicio irreparable. Al final, entonces, lo que trataría de hacer esta reforma no es otra cosa que colocar al presunto delincuente tributario en la misma posición que cualquier otro deudor fiscal, y eso supone, en efecto, la supresión de una antigua situación privilegiada de este tipo de delincuencia. En cuarto lugar, aunque sea de menor importancia, introduce algunas mejoras técnicas en la regulación de las defraudaciones a Hacienda y a los Presupuestos de la Unión Europea.

En quinto y último lugar, esta ley va a evitar la denuncia ante los Juzgados de aquellos obligados tributarios que han regularizado, de forma voluntaria y completa, su situación tributaria. Se trata, en tal caso, de la polémica regularización tributaria que se llevó a cabo durante el año 2012 por aquellos contribuyentes que quisieron acogerse a ella, también conocida como amnistía fiscal, amparada en el texto del Real Decreto-ley 12/2012, de 30 de marzo, por el que se introducen diversas medidas tributarias y administrativas dirigidas a la reducción del déficit público. ¿Fue justa, hay que plantearse, esta norma?

La Ley Orgánica 7/2012, de 27 de diciembre, en su preámbulo, contesta de manera positiva a la pregunta, estableciendo que "se considera que la regularización de la situación tributaria hace desaparecer el injusto derivado del inicial incumplimiento de la obligación tributaria”24. La consecuencia de ello fue la modificación del artículo 305.4 del Código Penal, que queda del siguiente modo: "La regularización por el obligado tributario de su situación tributaria impedirá que se le persiga por las posibles irregularidades contables u otras falsedades instrumentales que, exclusivamente en relación a la deuda tributaria objeto de regularización, el mismo pudiera haber cometido con carácter previo a la regularización de su situación tributaria”.

Ahora bien, esto no resuelve del todo la cuestión, más importante aún, de la constitucionalidad de esta amnistía fiscal y, por consiguiente, del cuestionamiento de su legalidad. Hay que recordar, entonces, que el Real Decreto-ley 12/2012, de 30 de marzo, establecía un mecanismo de regularización tributaria de los siguientes impuestos: IRPF, IS e IRNR. Según este mecanismo, aquellos contribuyentes que no hubieran declarado bienes, o simplemente dinero, estando obligados a ello por estos

\footnotetext{
${ }^{24}$ Más adelante, en la misma norma, refuerza su argumento, pues destaca que tanto la Fiscalía General Del Estado como el Tribunal Supremo "de forma muy expresiva se han referido a la regularización como el pleno retorno a la legalidad que pone fin a la lesión provisional del bien jurídico protegido producida por la defraudación consumada con el inicial incumplimiento de las obligaciones tributarias”.
} 
impuestos, podían hacerlo presentando una declaración especial y pagando solamente el $10 \%$ de su valor. Piénsese en cómo se sentirían aquellos contribuyentes, que habían cumplido escrupulosamente con sus obligaciones tributarias, que veían cómo se premiaba a los incumplidores. Por todo ello, hay argumentos en ambos sentidos ${ }^{25}$, que se pueden resumir del modo siguiente:

Por un lado, a favor de la constitucionalidad de la norma existen los argumentos del legislador, para el que la norma posee una suficiente y clara fundamentación legal de la medida de regularización tributaria, legitimada, especialmente, por las palabras del Tribunal Supremo citadas con anterioridad. Junto a ello, el legislador también aduce que el beneficio de la medida está limitado, pues impide la persecución penal de aquellas irregularidades fiscales "exclusivamente en relación a la deuda tributaria objeto de regularización”. De todos modos, se insiste en la existencia de otro requisito y límite más que, aunque sea técnico y casi podría sobrentenderse, no se debe olvidar: el reconocimiento y el pago de la deuda tributaria debe efectuarse antes de que el contribuyente haya recibido notificación de cualquier actuación en el sentido de determinar la deuda tributaria objeto de regularización por la Agencia tributaria o se haya producido denuncia o querella sobre la misma.

Por otro lado, en contra de la constitucionalidad de la norma existe la posible vulneración de algunos principios constitucionales ${ }^{26}$. Entre ellos, resulta conveniente referirse al artículo 9.3 de la Constitución que garantiza, entre otros, el principio de jerarquía normativa y el principio de seguridad jurídica. Pues bien, el Real Decreto-ley 12/2012, de 30 de marzo, en su disposición final primera, cambia la redacción del artículo 180.2 de la Ley General Tributaria al establecer el mayor beneficio que podía desear el antaño incumplidor tributario, ya que "la regularización practicada le exoneraría de su responsabilidad penal, aunque la infracción en su día cometida pudiera ser constitutiva de delito contra la Hacienda Pública”. Como poco, se podría afirmar lo sorprendente y curioso de que esa exención genérica de responsabilidad penal se implante en un Real Decreto-ley y no en una ley orgánica. Si esto no llega a vulnerar el principio de jerarquía normativa constitucional, al menos, se podrá decir que tropieza con el cumplimiento exquisito del mismo. La justificación material de esta norma consistente en mejorar la recaudación y el control de los bienes declarados también resulta, al menos, un sesgo a la seguridad jurídica importante.

Sin embargo, el principio constitucional que parece más vulnerado y lesionado por la aplicación del Real Decreto-ley 12/2012, de 30 de marzo, es el principio de igualdad, de una parte, recogido en el artículo 31.1 del texto constitucional como

\footnotetext{
${ }^{25}$ Véase, por su brillantez y claridad, el análisis realizado por M. A. SÁNCHEZ HUETE, "Medidas tributarias anticrisis de España. Análisis específico de la amnistía fiscal”, Revista de Derecho (Valdivia), vol. XXVI, $n^{\circ} 1$, julio de 2013, pp. 95-117.

${ }^{26}$ Véase una exposición convincente, y crítica, sobre las dudas de compatibilidad de la norma con determinados principios constitucionales en H. LÓPEZ LÓPEZ y R. CAMPIONE, "La regularización tributaria prevista en el Real Decreto-Ley 12/2012, de 30 de marzo: Una amnistía fiscal contraria a la justicia distributiva y manifiestamente ineficaz”, Eunomía. Revista en Cultura de la Legalidad, $\mathrm{n}^{\circ} 3$, septiembre de 2012-febrero de 2013, pp. 103-124.
} 
inspirador del sistema tributario y, de otra, consagrado en el artículo 14 del mismo texto. Al final, lo que esta norma supone es un trato discriminatorio ${ }^{27}$, al dar la posibilidad de que aquellos contribuyentes que no han cumplido sus obligaciones tributarias puedan hacerlo en condiciones más ventajosas que los cumplidores, pagando menos impuestos que los que les corresponderían y beneficiándose, por tanto, de una condonación parcial de su deuda tributaria. Todo esto, además, también conlleva el soportar el riesgo de que los ciudadanos entiendan que se premia la ilicitud y, por ello, desincentive el cumplimiento legal de las obligaciones tributarias ${ }^{28}$.

Pese a todo ello, el artículo 305.4 del Código Penal, de momento, sigue en vigor, así que se pueden plantear dos preguntas: ¿Se puede perseguir penalmente a los contribuyentes que han regularizado su situación tributaria? ¿Por qué delito o delitos podrían ser perseguidos entonces? La respuesta a ambas preguntas es negativa, ya que los contribuyentes que hayan regularizado su situación tributaria retornan plenamente a la legalidad, según el artículo mencionado, así que, consecuentemente, no existiría responsabilidad penal por el delito de blanqueo de capitales, al no existir ya delito fiscal previo. De hecho, esta conclusión ha sido expuesta con firmeza por la doctrina: "La eventual regularización que [un obligado tributario] pudiera llevar a cabo (conforme al art. 305.4 CP constituiría (como venía ocurriendo antes de la reforma de 2012) una excusa absolutoria del delito fiscal (insistimos en que el tipo correspondiente al blanqueo de capitales no resultaría aquí aplicable)" ${ }^{\text {,2 }}$. Por eso, no hay duda de que si no existe delito fiscal, faltaría el delito previo para que existiese el blanqueo, salvo en el caso de que ese dinero o esos bienes no declarados procediesen del narcotráfico, estafas u otros delitos.

En cambio, el delito fiscal parece, en principio y sin discusión, que puede identificarse y constituirse como una de esas actividades delictivas en las que se originaban los bienes que se mencionaban en el artículo 301.1 del Código Penal, que tipifica el blanqueo de capitales. Esto quiere decir que, aparentemente, no habría ningún problema en declarar el delito fiscal como el delito subyacente necesario para que exista el delito de blanqueo de capitales. La jurisprudencia ha tratado de establecerlo de ese modo. Sin ir más lejos, la sentencia del Tribunal Supremo núm. 974/2012, de 5 de diciembre, lo expone, en su fundamento jurídico trigésimo séptimo, del siguiente modo: "la cuota defraudada constituye un bien procedente de la actividad delictiva y, por lo

\footnotetext{
${ }^{27}$ De este modo se ha afirmado y explicado la vulneración del principio de igualdad: “al reconocerse una causa personal de supresión de la punibilidad que privilegia injustificadamente a determinados delincuentes sin que existan características diferenciales en sus conductas, pues nada tienen de especial los defraudadores tributarios anteriores al ejercicio fiscal 2012, de manera que este trato desigual, carente de razón deviene discriminatorio". M. ABEL SOUTO, "Blanqueo, innovaciones tecnológicas, amnistía fiscal de 2012 y reforma penal”, Revista Electrónica de Ciencia Penal y Criminología, nº 14, diciembre de 2012, p. 26.

${ }^{28}$ Semejantes dudas también son expuestas, como conclusión, tras estudiar la compatibilidad de la norma con varios principios constitucionales en J. M. IGLESIAS CASAIS y A. GONZÁLEZ MÉNDEZ, "La evasión fiscal y su "amnistía". La justicia tributaria en un contexto de crisis económica", Dereito: revista xurídica da Universidade de Santiago de Compostela, vol. 22, nº ext., noviembre de 2013, pp. 195-223.

${ }^{29}$ J. A. SANZ DÍAZ-PALACIOS, "Regularización tributaria y delito fiscal (art. 305.4 del Código Penal)”, Impuestos, no 11, noviembre de 2014, p. 111.
} 
tanto, objeto idóneo del blanqueo de capitales. En este sentido el Consejo General del Poder Judicial en su informe al anteproyecto de Ley, declaró expresamente que la cuota defraudada a la Hacienda Pública cuando constituye el producto de un delito fiscal, puede ser objeto de una operación de blanqueo, siempre que la cuota defraudada alcance el límite cuantitativo previsto en el tipo penal contra la Hacienda Pública”.

A pesar de la jurisprudencia, creemos que es indispensable determinar cuál es el supuesto que ha producido el delito fiscal. Recordemos que, como ya señalamos, el artículo 305 del Código Penal tipificaba los siguientes supuestos: elusión del pago de tributos, no ingresar cantidades retenidas (dinerarias o en especie) o no retener las que haya obligación de hacerlo, obtención indebida de devoluciones y disfrute indebido de beneficios fiscales. A nuestro juicio, el delito fiscal solamente puede ser delito previo al de blanqueo de capitales en los dos últimos supuestos: obtención indebida de devoluciones y disfrute indebido de beneficios fiscales. Ninguno de los otros supuestos del delito fiscal permitiría la existencia del blanqueo de capitales, ya que la simple tenencia de dinero no declarado procedente del trabajo legal y legítimo no significa que su origen sea ilícito. En ese caso concreto, su opacidad es ilícita, no su origen.

Algún autor, que comparte esta interpretación de limitar el delito fiscal que permite la existencia del blanqueo de capitales a los dos supuestos señalados, ha sido aún más contundente: "No son aceptables interpretaciones extensivas que van mucho más allá de la finalidad de la norma penal, incluso extravagantes, que vulneran, por tanto, el principio de legalidad penal, como aquella tesis que sostiene que el dinero que se ahorra quien no paga un impuesto es un dinero que tiene un origen delictivo. $\mathrm{Ni}$ ontológica ni normativamente puede ser aceptada esta idea” ${ }^{30}$.

\section{REFLEXIONES FINALES}

Según hemos visto, no siempre que existe delito fiscal existe blanqueo de capitales. Habrá que examinar qué supuesto tipificado como delito fiscal es el que se ha cometido para saber si puede existir delito de blanqueo de capitales. También hemos explicado que la jurisprudencia, por el contrario, sostenía que la cuota defraudada puede ser objeto de blanqueo. Son dos posturas, casi antagónicas, que no sabemos si están condenadas a entenderse en un futuro, pero hay que destacar que, incluso, este mismo año la sentencia del Tribunal Supremo núm. 265/2015, de 29 de abril, ha modificado la jurisprudencia anterior llegando a la misma conclusión que nosotros hemos defendido, aunque utilizando distinta argumentación ${ }^{31}$.

\footnotetext{
30 J. A. CHOCLÁN MONTALVO, “¿Puede ser el delito fiscal delito precedente del delito de blanqueo de capitales?", Boletín del Ilustre Colegio de Abogados de Madrid, n 37, septiembre de 2007, p. 160. El autor ha mantenido íntegramente su opinión, según puede comprobarse en su libro La aplicación práctica del delito fiscal: cuestiones y soluciones, Bosch, Barcelona, 2011, p. 339.

${ }^{31}$ Véase un muy buen resumen de esta STS en V. A. GARCÍA MORENO, "Recientes aportaciones del Tribunal Supremo en autoblanqueo y su eventual incidencia en el delito fiscal”, Carta Tributaria. Revista de Opinión, № 3, Junio de 2015.
} 
El Tribunal Supremo, en esta sentencia, va a poner el énfasis en que los bienes que se adquieran, posean, utilicen, conviertan o transmitan originados en una actividad delictiva, para que exista blanqueo, tienen que cumplir, según el artículo 301.1 del Código Penal, uno de estos dos determinados fines: “ocultar o encubrir su origen ilícito, o para ayudar a la persona que haya participado en la infracción o infracciones a eludir las consecuencias legales de sus actos”. Por eso, el mero disfrute de los bienes no supone blanqueo de capitales, resultando preceptiva la existencia de alguna de esas dos finalidades mencionadas. Habrá, por tanto, que separar, en los posibles casos de blanqueo de capitales derivados de un delito fiscal, conductas tales como los actos más básicos de consumo -alimentación, alojamiento, vestido, etc.- de los que no lo son. Dicho de otro modo, diferenciar lo que son gastos comunes de lo que son inversiones, pues estas últimas, no se puede negar, se revelan mucho más idóneas para producir la transformación de ese dinero ilícito en, al menos aparentemente, lícito.

Esta sentencia comentada, pese a significar un importante avance en el conocimiento de la relación entre el delito de blanqueo de capitales y el delito tributario, no creemos que sea definitiva. El blanqueo de capitales y el delito fiscal son temas jurídicos amplios y complejos, que se nutren de factores ajenos al Derecho en ocasiones, como cuando las cuestiones económicas o políticas inciden o impulsan reformas legislativas que les afectan. Por ello, no es demasiado atrevido asegurar que continuarán modificándose y habrá que estar atento a la interpretación de los elementos esenciales de ambos delitos, y de su posible relación, que lleve a cabo la jurisprudencia, sobre todo, pero también, la doctrina, que nunca deja de ser importante, aunque solo fuera por la capacidad de proponer reformas normativas tributarias o de cualquier otro tipo $^{32}$.

\footnotetext{
${ }^{32}$ A título de ejemplo, se ha propuesto la "creación de un impuesto ad hoc, que grave los movimientos de activos desde España a un territorio fiscalmente opaco, realizados directamente o empleando jurisdicciones intermedias. Tendrá finalidad informativa y disuasiva, admitiéndose prueba de la justificación económica de la operación, como causa de exención”. C. M. LÓPEZ ESPADAFOR y L. M. LOMBARDERO EXPÓSITO, "Revisión de la problemática de los paraísos fiscales y su incidencia en el blanqueo de capitales", Estudios financieros. Revista de contabilidad y tributación: Comentarios y casos prácticos, $\mathrm{n}^{\circ}$ 323, febrero de 2010, p. 54.
} 